\title{
Incidence of retrorenal colon during percutaneous nephrolithotomy
}

\author{
Mehmet Balasar ${ }^{1}$, Abdülkadir Kandemir ${ }^{1}$, Necdet Poyraz ${ }^{1}$, Yunus Unal ${ }^{1}$, Ahmet Ozturk ${ }^{1}$ \\ ${ }^{1}$ Department of Urology, Necmettin Erbakan University Meram Medical School, Konya, Turkey
}

\section{ABSTRACT}

Objective: The aim of this study was to investigate retrorenal colon incidence in percutaneous nephrolithotomy (PNL) interventions made in our clinic.

Materials and Methods: Clinical data of 804 PNL patients, accumulated over a 7 year period (2006-2012), was surveyed. The patient files were reviewed retrospectively, and only those who had abdominal computed tomography (CT) images before PNL intervention were included in the study. In the CT images, the position of both the ascending and descending colon in relation to the right and left kidneys were evaluated.

Results: According to our hospital reports, 394 patients with CT images were included in the present study 27 patients (6.9\%) had retrorenal colon, of which 18 (4.6\%) were on the left side, $4(1.0 \%)$ on the right side and 5 (1.3\%) had bilateral retrorenal colons. Colonic perforation complication was seen only in two patients and the colonic perforation rate was $0.3 \%$. These two cases had no CT images.

Conclusions: PNL, in the process of becoming the standard treatment modality, is a safe and reliable technique for renal stone treatment. Colonic injury should be taken into consideration during PNL interventions of the lower pole of the kidney (especially on the left side) due to the location of retrorenal colon.

\section{ARTICLE INFO}

\section{Key words: \\ Colon; Tomography, X-Ray \\ Computed; Nephrostomy, \\ Percutaneous}

Int Braz J Urol. 2015; 41: 274-8

Submitted for publication:

January 24, 2014

Accepted after revision:

June 08, 2014

\section{INTRODUCTION}

Percutaneous Nephrolithotomy (PNL) is a common treatment option for patients with renal stones. PNL applications are mostly safe and associated with a low but specific complication rate. These emerge during initial puncture and lead to injuries in the surrounding organs (e.g., colon, pleural cavity, lung, spleen, liver, and duodenum) (1). The most distressing one among these complications are colonic perforations. Though very rare, they may lead to morbidity in the form of septicemia, peritonitis, abscess formation, and nephrocolic or colocutaneous fistula. Hence, knowing the position of the retrorenal colon to prevent surgical complications during PNL and other surgical modalities is a priority. In the present manuscript, we studied the number of retrorenal colon presence in the CT images taken before PNL applications.

\section{MATERIALS AND METHODS}

The medical records of 804 patients who underwent PNL in our clinic from 2006 to 2012 were reviewed retrospectively. PNL was conducted in the prone position and under fluoroscopic guidance. Patients' CT images taken before PNL were studied for the position of both the ascending and descending colon in relation to the right and left kidneys respectively. 
Patients without CT images and patients with severe musculoskeletal defects, abdominal masses, previous surgery, renal abnormalities (large renal cysts, ectopic kidney, and horseshoe kidney) and ascites were excluded from the study. Hence, CT images of only 394 cases were included in our study. All CT images taken in supine position were evaluated by the same radiologist for retrorenal colon presence.

CT images were as previously identified (2); to the horizontal plane a parallel line was drawn through the posterior edge of each kidney (posterior renal line) at three renal levels: upper pole, middle pole and lower pole. The number of cases with partial colon extension posterior to the posterior renal line was determined. These were further separated to see if any part of the colon extended directly behind the lower pole (Figures 1-4), middle pole and upper pole of the kidney.

\section{RESULTS}

Of the 394 patients included in the present study, 178 were female and 216 were male with a mean age of 42.2 years. 27 patients (6.9\%) had retrorenal colon with $18(4.6 \%)$ on the left and $4(1.0 \%)$ on the right side. The other $5(1.3 \%)$ patients had bilateral retrorenal colons (Table-1). In comparison to kidney location, the retrorenal colons of all patients were at the lower poles.

During the studied period, colonic perforation was observed in only 2 cases $(0.3 \%)$ that did not had CT scans taken before PNL intervention.

\section{DISCUSSION}

PNL was first described in 1976 and has become in the last 30 years almost the standard treatment modality for renal stones (3). Despite

Figures 1-4 - Anatomical variations of colon related to the kidney: Colon extended directly behind the lower pole.
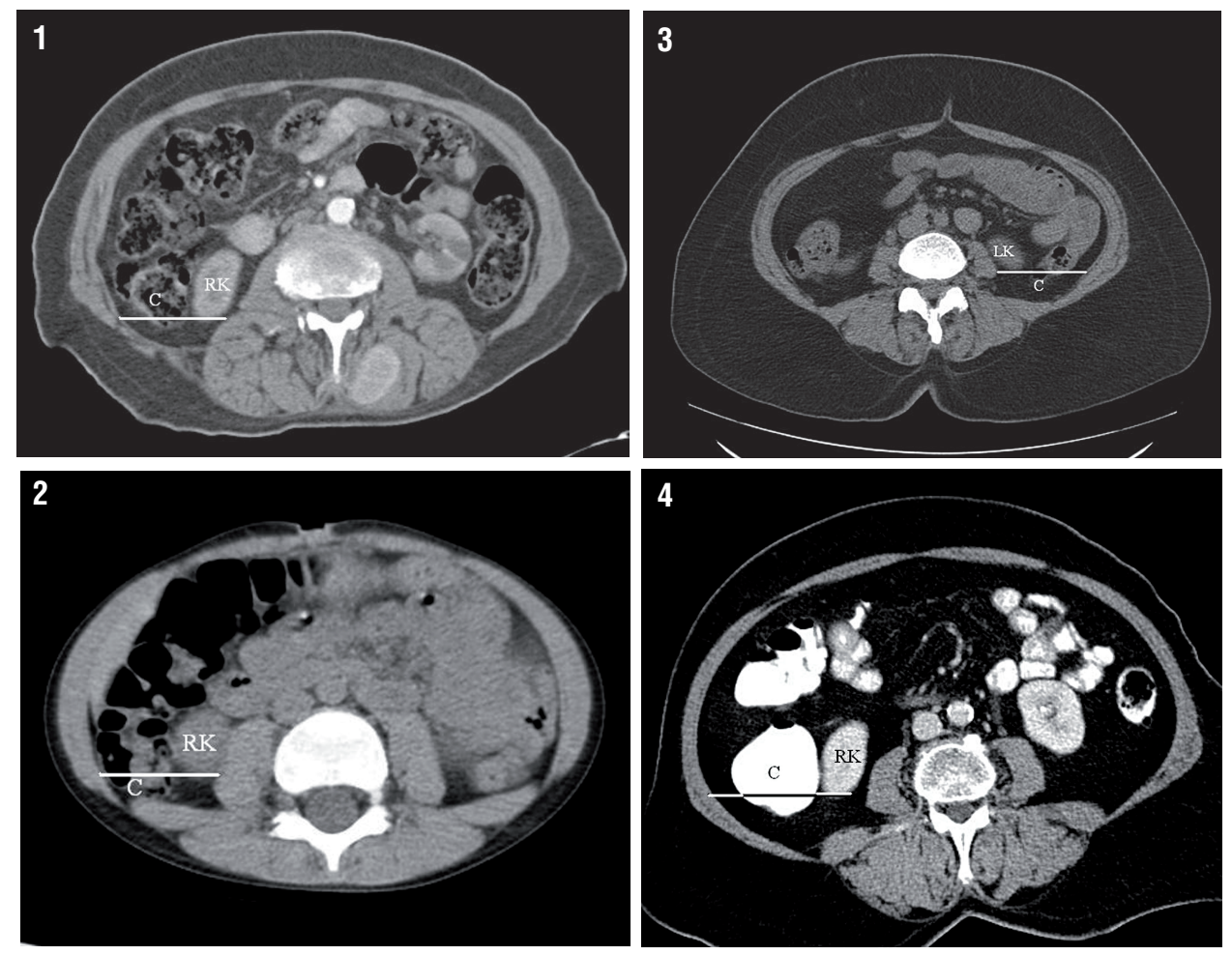

RK = Right Kidney, $\mathbf{L K}=$ Left Kidney, $\mathbf{C}=$ Colon 
Table 1 - Distribution of retrorenal colon according to kidney level.

\begin{tabular}{lcccc}
\hline Level & Left & Right & Bilateral & Total \\
\hline Upper & 0 & 0 & 0 & 0 \\
Middle & 0 & 0 & 0 & 0 \\
Lower & 18 & 4 & 5 & 27 \\
Total & 18 & 4 & 5 & 27 \\
\hline
\end{tabular}

the high success rates, it is still an invasive procedure associated with significant morbidity that involves life-threatening complications.

PNL outcome depends heavily on planning and successful execution of initial kidney access as it may carry an increased risk of damage to surrounding organs. In order to gain access to the desired renal calyx with minimal complications it is necessary to evaluate renal anatomy and the surrounding organs.

An essential part of PNL tract planning is radiological imaging. Intravenous urography (IVU) has historically been the main preoperative imaging technique for PNL. The spread and increasing presence of multiphase CT scanners has made it the main imaging preference in many centers. IVU however still remains valuable for the preoperative planning and evaluation of kidney stones due to its ability to demonstrate fine details in the collecting system anatomy of the kidney. But a poorly performed IVU may have limit valuable information required before PNL application. Therefore, dynamic CT has recently become the gold standard in urolithiasis diagnosis and evaluation (4). CT used for the diagnosis of renal stones, also delineates the extent, orientation, and location of the stones within the kidney and thus enable the most suitable PNL tract selection. Moreover, by showing the relationship of the kidney and stone to the surrounding structures enables to minimize the risks of injury to the spleen, liver, or to an unsuspected retrorenal colon.

Pre and post PNL related complications rate up to $83 \%$, including extravasation, transfusion, and fever; yet, major complications such as septicemia and colonic or pleural injury are rare
(5). One of the most distressing complication ofn PNL is colonic perforation.

Colonic perforation, a rare complication of PNL, is reported in less than 1\% of cases (6). During PNL, the age of the patient, existence of horse shoe kidney, previous kidney surgery, left kidney inferior location access, lateral posterior axillary line access, hypermobile kidney, and the existence of retrorenal colon are among the factors that predispose to colon perforation $(5,7)$.

A retrorenal colon is more frequently found on the left side and is most likely to be situated near the inferior kidney pole (8). Retrorenal colon is found in approximatively $0.6 \%$ of the general population according to the Hadar-Gadot and Sherman et al. study $(9,10)$. In another study with 333 participants, CT images showed that the left colon was posterior in $16.1 \%$ of cases, and the right colon was posterior in $9 \%$ of cases at the level of the lower pole (11). Total ratio of retrorenal colon was $1.7 \%$, with $1.2 \%$ on the left side, $0.3 \%$ on the right side and $0.2 \%$ bilateral in the Atar et al. study (2). Hopper et al. reported in their study based on 500 abdomen CT scans that the overall frequency of retrorenal colon was 1.9\% if the images were taken in supine position. When 90 patients were studied in the prone position, retrorenal colon was found in $10 \%$ (12). In the present study, retrorenal colon in PNL patients was found in 27 cases, (6.9\%) of which $18(4.6 \%)$ were on the left side, $4(1.0 \%)$ on the right side, and $5(1.3 \%)$ bilateral.

All CT scans in the present study were performed in supine position. However, in the literature the prevalence of retrorenal colon varies according to the patients' position. Hopper et. al. study, analyzing a series of 500 supine and 90 prone abdominal CT scans, determined the colon positioned posterior to the kidney in $1.9 \%$ and $10 \%$ of cases, respectively. They found that there is a high risk of colon perforation during PNL in the prone position (13). If supine and prone positioned patient images are to be compared, the prone position seems to be associated with a significantly shorter nephrostomy tract length and a greater number of potential puncture sites. A shorter tract length may ease percutaneous access and nephroscope mobility within the collecting 
system and thus improve stone-free rate and decrease hematuria risk. A greater range of potential access angles may result in decreased risk of visceral injury (14). In the CROES PNL study group 1079 PNL applications were conducted in prone and 232 in supine positions without revealing a difference in complication rates (15).

PNL was applied a short time ago mainly in endourology clinics; yet, PNL related complications were generally documented by authors and departments whose main interest is PNL. However, nowadays PNL has become a routine practice in all urology clinics and the reported complications may differ from the actual ones. In the present study, the retrorenal colon rate of $6.9 \%$ of patients who underwent PNL shows actually how close the urologists are to intervene to a retrorenal colon perforation.

Unfortunately, in the two retrorenal colon perforation cases, no CT images were taken before PNL intervention and thus our ability to evaluate colon perforation risk proactively was nullified. On the other hand, no colon perforations occurred in any of the cases who had CT images obtained before PNL intervention. In order to prevent colon perforation during PNL, alternative imaging techniques are available. However, a precise and reliable standardization of imaging techniques seems currently not possible. Thus, ultrasound or CT guided puncture to the kidney calyx, in cases with previously reported anatomic variations without inflicting harm to other organs, might be used. Moreover, 3D CT can provide excellent representation of kidney anatomy and be used while planning a PNL intervention; however, it does not show the relationship between the calices and different organs, such as the colon in particular and kidney motion (16).

\section{CONCLUSIONS}

CT is the most commonly used diagnostic method for identifying retrorenal colon location variation. Retrorenal colon is more frequently found on the left side and on the lower pole of the kidney. Therefore, when accessing the lower pole of the kidney, especially on the left side, the risk of colonic injuries should be considered during PNL.

\section{CONFLICT OF INTEREST}

\author{
None declared.
}

\section{REFERENCES}

1. Rudnick DM, Stoller ML. Complications of percutaneous nephrostolithotomy. Can J Urol. 1999;6:872-5.

2. Atar M, Hatipoglu NK, Soylemez H, Penbegul N, Bozkurt Y, Gumus $\mathrm{H}$, et al. Relationship between colon and kidney: a critical point for percutaneous procedures. Scand J Urol. 2013;47:122-5.

3. Fernström I, Johansson B. Percutaneous pyelolithotomy. A new extraction technique. Scand J Urol Nephrol. 1976;10:257-9.

4. Miller NL, Lingeman JE. Management of kidney stones. BMJ. 2007;334:468-72.

5. Michel MS, Trojan L, Rassweiler JJ. Complications in percutaneous nephrolithotomy. Eur Urol. 2007;51:899-906; discussion 906.

6. Vallancien G, Capdeville R, Veillon B, Charton M, Brisset JM. Colonic perforation during percutaneous nephrolithotomy. J Urol. 1985;134:1185-7.

7. El-Nahas AR, Shokeir AA, El-Assmy AM, Shoma AM, Eraky I, El-Kenawy MR, et al. Colonic perforation during percutaneous nephrolithotomy: study of risk factors. Urology. 2006;67:937-41.

8. LeRoy AJ, Williams HJ Jr, Bender CE, Segura JW, Patterson $\mathrm{DE}$, Benson RC. Colon perforation following percutaneous nephrostomy and renal calculus removal. Radiology. 1985;155:83-5.

9. Hadar H, Gadoth N. Positional relations of colon and kidney determined by perirenal fat. AJR Am J Roentgenol. 1984;143:773-6.

10. Sherman JL, Hopper KD, Greene AJ, Johns TT. The retrorenal colon on computed tomography: a normal variant. J Comput Assist Tomogr. 1985;9:339-41.

11. Boon JM, Shinners B, Meiring JH. Variations of the position of the colon as applied to percutaneous nephrostomy. Surg Radiol Anat. 2001;23:421-5.

12. Hopper KD, Sherman JL, Luethke JM, Ghaed N. The retrorenal colon in the supine and prone patient. Radiology. 1987;162:443-6.

13. Hopper KD, Sherman JL, Williams MD, Ghaed N. The variable anteroposterior position of the retroperitoneal colon to the kidneys. Invest Radiol. 1987;22:298-302.

14. Duty B, Waingankar N, Okhunov Z, Ben Levi E, Smith A, Okeke Z. Anatomical variation between the prone, supine, and supine oblique positions on computed tomography: implications for percutaneous nephrolithotomy access. Urology. 2012;79:67-71. 
15. Astroza G, Lipkin M, Neisius A, Preminger G, De Sio M, Sodha $\mathrm{H}$, et al. CROES PNL Study Group. Effect of supine vs prone position on outcomes of percutaneous nephrolithotomy in staghorn calculi: results from the Clinical Research Office of the Endourology Society Study. Urology. 2013;82:1240-4.
16. Goger E, Guven S, Gurbuz R, Yilmaz K, Kilinc M, Ozturk A. Management of a colon perforation during pediatric percutaneousnephrolithotomy.JEndourol.2012;26:1118-20.

Correspondence address:

Mehmet Balasar, M.D

Department of Urology

Necmettin Erbakan University Meram Medical School 42080 Akyokus Konya, Turkey

Telephone: +53 25 174-613

E-mail:drbalasar@hotmail.com 